\title{
Implementasi Framework Cobit 5 Fokus Domain (MEA) dalam Evaluasi Tata Kelola Teknologi Informasi Pada Dinas Komunikasi Informatika dan Statistik Provinsi Riau
}

\author{
Hadi Asnal ${ }^{*}$, Prilly Maya Gita ${ }^{2}$ \\ ${ }^{1 *}$ STMIK Amik Riau \\ "hadi.asnal27@gmail.com
}

\begin{abstract}
The Office of Informatics Communication and Statistics of Riau Province, especially in the field of e-government services, needs to do a study to find out whether the use of information technology has reached the desired target, so far the utilization of technology in the service has not been proven whether it has been going well or not, on this basis it is necessary to evaluate the information technology governance of the Office of Information Communication and Statistics of the Riau Province. In the implementation of information technology governance requires monitoring and evaluation that aims to monitor the course of the evaluation process. Data collection methods used are data analysis, interviews and questionnaires. COBIT 5 is a framework that has a variety of needs needed by management while taking into account the risks that may be present and used to determine the maturity level of information technology governance. COBIT 5 has several domains, but the MEA (Monitor, Evaluate and Assess) domain, especially MEA02, was chosen because it is relevant to the problems described above, where the use of technology in the Office of Informatics Communication and Statistics of Riau Province, especially in the field of e-government services has not been carried out monitoring, evaluations, and assessments that refer to the Information Systems Audit and Control Association (ISACA) standard as explained (ISACA) MEA domain has 3 sub domains namely Monitor, Evaluate and Assess Performance and Performance (MEA01), Monitor, Evaluate and Assess the System of Internal Control (MEA02), and Monitor, Evaluate and Assess Compliance with External Requirements (MEA03), but in this study only focus on the domain Monitor, Evaluate, and Assess the System of Internal Control (MEA02). From the evaluation that has been carried out, it is found that the capability level results, the maturity level of information technology governance in the Riau Provincial Information and Information Communication Office in the field of egovernment services using the MEA02 domain are at the level of 3.92 or it can be stated that the achievements in each process have not been fulfilled. as a whole and has not yet achieved the goals expected by Diskominfotik Riau Province.
\end{abstract}

Keywords : IT Audit, COBIT 5, IT Governance, MEA

\begin{abstract}
Abstrak
Dinas Komunikasi informatika dan Statistik Provinsi Riau khususnya pada bidang layanan e-government perlu dilakukan kajian untuk mengetahui apakah penggunaan teknologi informasi sudah mencapai target yang diinginkan, sejauh ini pemanfaatan teknologi pada dinas tersebut belum dapat dibuktikan apakah telah berjalan dengan baik ataupun belum, atas dasar ini perlu dilakukan evaluasi dari tata kelola teknologi informasi Dinas Komunikasi informatika dan Statistik Provinsi Riau. Dalam pelaksanaan tata kelola teknologi informasi tersebut membutuhkan monitoring dan evaluasi yang bertujuan untuk memantau jalannya proses evaluasi tersebut. Metode pengumpulan data yang digunakan yaitu analisis data, wawancara dan kuisioner. COBIT 5 merupakan suatu framework yang memiliki beragam kebutuhan yang dibutuhkan oleh manajemen dengan tetap memperhatikan resiko yang mungkin hadir dan digunakan untuk mengetahui tingkat kematangan tata kelola teknologi informasi. COBIT 5 memiliki beberapa domain, namun domain MEA (Monitor, Evaluate and Assess) khususnya MEA02 dipilih karna relevan dengan masalah yang telah dijelaskan diatas, dimana penggunaan teknologi pada Dinas Komunikasi informatika dan
\end{abstract}


Statistik Provinsi Riau khususnya pada bidang layanan e-government belum ada dilakukan monitoring, evaluasi, maupun penilaian yang merujuk sesuai standar Information Systems Audit and Control Association (ISACA) sebagaimana dijelaskan (ISACA) domain MEA memiliki 3 sub domain yaitu Monitor, Evaluate and Assess Performance and Conformance (MEA01), Monitor, Evaluate and Assess the System of Internal Control(MEA02), dan Monitor, Evaluate and Assess Compliance with External Requirements (MEA03), namun dalam penelitian ini hanya berfokus pada domain Monitor, Evaluate, and Asess the System of the Internal Control (MEA02). Dari evaluasi yang telah dilakukan maka ditemukan hasil capability level, tingkat kematangan tata kelola teknologi informasi pada Dinas Komunikasi Informatika dan Statistik Provinsi Riau di bidang layanan e-government menggunakan domain MEA02 berada pada level 3,92 atau dapat dimaksud bahwa pencapaian pada setiap prosesnya belum terpenuhi secara keseluruhan dan belum mencapai tujuan yang diharapkan oleh Diskominfotik Provinsi Riau.

Kata kunci : Audit TI, COBIT 5, Tata Kelola TI, MEA.

\section{Pendahuluan}

Pengelolaan teknologi informasi merupakan bagian penting dalam berjalannya berbagai aktifitas disebuah organisasi, semakin baik pengelolaan teknologi informasi pada suatu organisasi maka akan berdampak baik pula pada banyak aspek, pada akhirnya Pengelolaan teknologi informasi yang baik akan mendukung tujuan suatu organisasi. Sedangkan tata kelola teknologi informasi merupakan proses dan kontrol terhadap seluruh infrastruktur teknologi informasi, proses dan kontrol yang maksud akan melibatkan banyak pihak yang dianggap memiliki kepentingan. Tata kelola TI menurut Sihotang \& Sagala adalah suatu struktur dan proses yang saling berhubungan serta mengarahkan dan mengendalikan insatansi dalam pencapaian tujuan perusahaan melalui nilai tambah dan penyeimbangan antara resiko dan manfaat dari teknologi informasi serta prosesnya [1].

Menurut Prasetyo \& Mariana Tata kelola TI atau IT (Information Technology) Governance merupakan struktur hubungan dan proses untuk mengarahkan dan mengendalikan organisasi untuk mencapai tujuannya dengan menambahkan nilai ketika menyeimbangkan risiko dibandingkan dengan TI dan prosesnya [2]. Sedangkan E-Government menurut Satria \& Hartati merupakan program dan komitmen pemerintah dalam upaya untuk mengembangkan penyelenggaraan kepemerintahan yang berbasis elektronik serta melakukan transformasi guna memfasilitasi kegiatan masyarakat dan kalangan bisnis untuk menuju masyarakat yang berbasis pengetahuan (Knowledge-based Society). Melalui pengembangan e-governmnet, pemerintah mengharapkan dapat dilakukan sistem manajemen dan proses kerja di lingkungan pemerintah dan pemerintah daerah otonom dengan mengoptimasikan pemanfaatan teknologi informasi dan komunikasi [3].

Dinas Komunikasi Informatika dan Statistik Provinsi Riau atau disingkat (Diskominfotik) merupakan sebuah instansi pemerintahan yang bertugas membantu gubernur dalam menjalakan aktifitas pemerintahan yang menjadi kewenangan daerah dan tugas pembantuan yang ditugaskan kepada daerah. Diskominfotik telah menggunakan teknologi Informasi dalam menjalakan fungsinya, hampir seluruh rencana kerja hingga implementasi sudah bergantung pada teknologi informasi.

Namun permalasahan yang ditemukan yaitu belum adanya evaluasi tata kelola TI pada Diskominfotik provinsi riau khususnya monitoring, evaluasi, maupun penilaian yang merujuk sesuai standar Information Systems Audit and Control Association (ISACA), sehingga pemanfaatan teknologi pada dinas tersebut belum dapat dibuktikan apakah telah berjalan dengan baik atau belum. Audit TI sendiri merupakan proses pengumpulan dan evaluasi bukti-bukti untuk menentukan apakah sistem komputer yang digunakan telah dapat melindungi aset milik organisasi, mampu menjaga integritas data, dapat membantu 
pencapaian tujuan pada organisasi tersebut secara efektif, serta menggunakan sumber daya yang dimiliki secara efisien. Audit pada dasarnya adalah proses sistematis dan obyektif dalam memperoleh dan mengevaluasi buktibukti tindakan ekonomi, guna memberikan asersi/pernyataan dan menilai seberapa jauh tindakan ekonomi sudah sesuai dengan kriteria yang berlaku dan mengkomunikasikan hasilnya kepada pihak terkait [4].

Berdasarkan permasalahan yang telah dipaparkan diatas, maka perlu dilakukan evaluasi teknologi informasi di Diskominfotik khususnya pada bidang layanan e-government dengan menggunakan framework COBIT 5. Untuk mengetahui apakah sistem sudah berjalan dengan baik dan dapat mencapai target yang diinginkan dan juga dapat meminimalisir resiko yang terjadi. Evaluasi teknologi informasi ini dilakukan menggunakan framework COBIT 5.

Menurut ISACA (2012), COBIT 5.0 adalah salah satu kerangka bisnis untuk tata kelola dan manajemen perusahaan IT. Versi evolusiner ini menggabungkan pemikiran terbaru dalam tata kelola perusahaan dan teknik manajemen, serta menyediakan prinsipprinsip, praktek, alat-alat analisis dan model yang diterima secara global untuk membantu meningkatkan kepercayaan, dan nilai dari sistem informasi. COBIT 5 membangun dan memperluas COBIT 4.1 dengan mengintegrasikan kerangka besar lainnya, standar dan sumber daya, termasuk ISACA Val-IT dan Risiko TI, Technology Infrastructure Library $\left(I T I L^{\circledR}\right)$ dan standar yang terkait dari International Organization for Standardization (ISO) [5].

COBIT 5 (Control Objectives for Information and Related Technology) juga dapat disebut sebagai framework tata kelola TI untuk mencapai kesenjangan antara masalah teknis, risiko bisnis dan kebutuhan control. Fokusnya yaitu pada domain Monitor, Evaluate and Assess (MEA02), COBIT 5 memiliki beberapa domain, namun domain MEA (Monitor, Evaluate and Assess) khususnya MEA02 dipilih karna relevan dengan masalah yang telah dijelaskan diatas, dimana penggunaan teknologi pada Dinas Komunikasi informatika dan Statistik Provinsi Riau khususnya pada bidang layanan egovernment belum ada dilakukan monitoring, evaluasi, maupun penilaian yang merujuk sesuai standar Information Systems Audit and Control Association (ISACA).

Nantinya akan ditemukan nilai kapabilitas saat ini, yang dapat menjadi acuan bagi kepala dinas untuk mentukan perbaikan kedepannya khsusnya dalam penggunaan infrastruktur teknologi informasi di Diskominfotik provinsi Riau. Dengan adanya audit teknologi informasi ini juga ditargetkan mampu memberikan informasi hingga rekomendasi tata kelola teknologi informasi di Diskominfotik Provinsi Riau.

\section{Metoda Penelitian}

\subsection{Kerangka Berfikir}

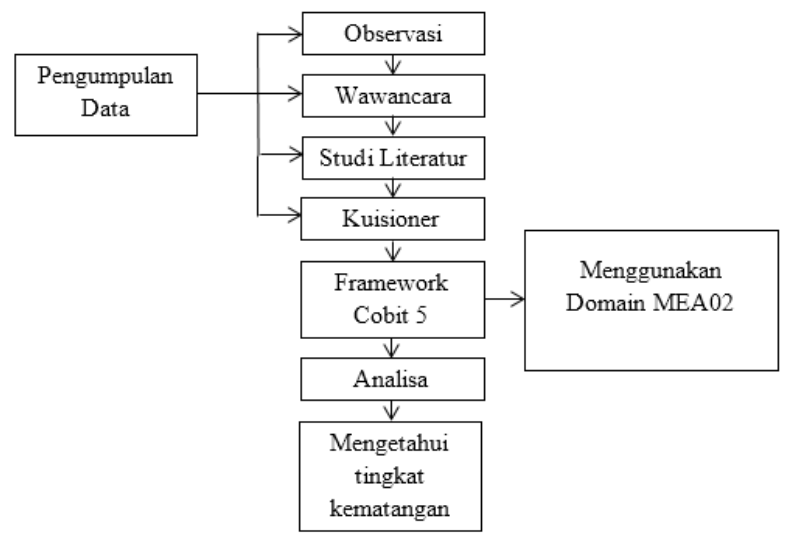

Gambar 1. Kerangka Berpikir Penelitian

\subsection{Tahapan Penelitian Dalam Cobit 5}

Pada tahap ini dilakukan analisa data dan perancangan, berupa penggunaan tools dan metodologi terhadap data yang didapat. Dalam melaksanakan tahap ini peneliti menggunakan kerangka kerja COBIT 5. Ada tahapan metode implementasi tata kelola teknologi informasi pada COBIT 5 yang dilakukan oleh peneliti, yaitu : 


\section{a. Initiate Programme}

Pada tahap ini menjelaskan tentang apa penggerak pada organisasi dan identifikasi pendorong perubahan saat ini. Tujuannya adalah memperoleh pemahaman tentang organisasi yang terdiri dari tujuan, tugas dan wewenang, pendekatan pengelolaan organisasi saat ini dan konsep program organisasi. Pada tahap ini diperoleh data dari hasil wawancara dengan narasumber di Dinas Komunikasi, Informatika, dan Statistika Provinsi Riau berkaitan dengan tugas dan wewenang, tugas pokok dan fungsi dan struktur organisasi. Pada tahapan ini juga digambarkan diagram RACI sebagai gambaran tugas di Dinas Komunikasi, Informatika, dan Statistika Provinsi Riau yang mengacu pada COBIT 5.

\section{b. Define Problems and Opportunities}

Pada tahap ini dilakukan penentuan tingkat kemampuan Dinas Komunikasi, Informatika, dan Statistika Provinsi Riau saat ini dalam mengelola teknologi informasi. Penentuan tingkat kemampuan saat ini dilakukan melalui kuisioner capability level yang diberikan kepada responden yang telah ditentukan sebelumnya. Tahapan ini meliputi : Pengolahan Data Responden, Perhitungan Capability Level saat ini dan Pengumpulan Hasil Temuan.

\section{Hasil Penelitian}

\subsection{Raci Chart}

RACI chart menggambarkan peranperan dari para pemangku kepentingan di Dinas Komunikasi, Informatika dan Statistik Provinsi Riau yang terkait langsung dengan proses yang diambil dalam pengelolaan TI. Proses yang diambil dalam tata kelola teknologi informasi di Dinas Komunikasi, Informatika dan Statistik Provinsi Riau adalah proses pada domain MEA02 yaitu Monitor, Evaluate and Assess the System of Internal Control (Memantau, Mengevaluasi dan Menilai Sistem Pengendalian Internal.). Peranperan pada RACI chart tersebut kemudian dipetakan kedalam peran-peran yang ada pada bagian struktur organisasi di Dinas Komunikasi, Informatika dan Statistik Provinsi Riau sesuai dengan struktur organisasi yang ada. RACI chart ini digunakan untuk penggambaran responden dalam kuesioner capability level yang akan diberikan.

\section{Identifikasi RACI Chart MEA02}

Pada identifikasi RACI chart untuk domain MEA02 yang penulis pilih mengacu pada pedoman tabel RACI dari standarisasi ISACA. Menurut (Hartanto \& Tjahyanto, 2010) yang dikutip dari IT Governance Institute, responden wawancara dan kuesioner yang dipilih berdasarkan tabel RACI Chart COBIT adalah responden yang mewakili dari tabel RACI tersebut untuk proses pengolahan data.

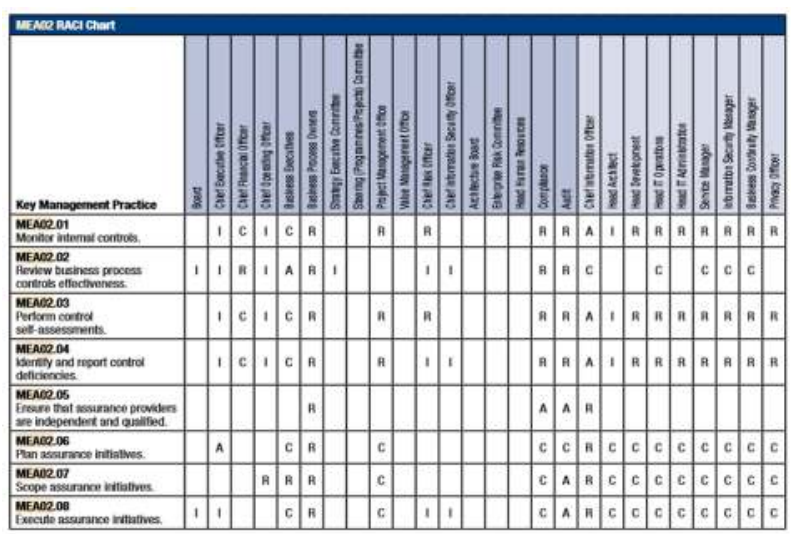

Gambar 2. COBIT 5 RACI Chart MEA02

(Standar ISACA, 2012

Tabel 1. Key Governance Practice COBIT 5

\begin{tabular}{|c|l|l|}
\hline No. & $\begin{array}{c}\text { Key } \\
\text { Governance } \\
\text { Practice } \\
\text { COBIT 5 }\end{array}$ & $\begin{array}{c}\text { Struktur Fungsional } \\
\text { Dinas Komunikasi } \\
\text { Informatika dan Statistik }\end{array}$ \\
\hline 1 & $\begin{array}{l}\text { Bussiness } \\
\text { Continuity } \\
\text { Manager }\end{array}$ & $\begin{array}{l}\text { Kasi Pengembangan Aplikasi } \\
\text { Pemerintah }\end{array}$ \\
\hline 2 & $\begin{array}{l}\text { Service } \\
\text { Manager }\end{array}$ & $\begin{array}{l}\text { Kasi Pengembangan Aplikasi } \\
\text { Publik }\end{array}$ \\
\hline 3 & $\begin{array}{l}\text { Chief } \\
\text { Executive } \\
\text { Officer }\end{array}$ & $\begin{array}{l}\text { Kasi Tata Kelola } e- \\
\text { government }\end{array}$ \\
\hline
\end{tabular}


Berikut penulis memetakan RACI Chart dengan struktur fungsional di Diskominfotik Provinsi Riau.

Tabel 2. RACI Chart MEA02 Diskominfotik Provinsi Riau

\begin{tabular}{|c|c|c|c|}
\hline $\begin{array}{l}\text { RACI : } \\
\text { Responsible (orang yang } \\
\text { melakukan kegiatan) } \\
\text { Accountable (orang yang } \\
\text { akhirnya bertanggung jawab } \\
\text { dan memiliki otoritas untuk } \\
\text { memutuskan suatu perkara) } \\
\text { Consulted (orang yang } \\
\text { diperlukan umpan balik atau } \\
\text { sarannya dan berkontribusi } \\
\text { akan kegiatan tersebut) } \\
\text { Informed (orang yang perlu } \\
\text { tahu hasil dari suatu keputusan } \\
\text { atau tindakan) }\end{array}$ & 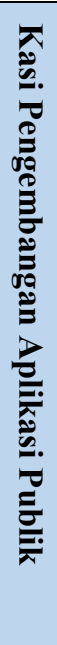 & 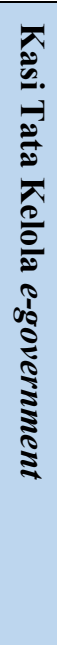 & 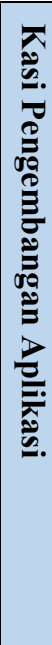 \\
\hline $\begin{array}{l}\text { MEA02.01 Monitor internal } \\
\text { controls }\end{array}$ & $\mathrm{R}$ & I & $\mathrm{R}$ \\
\hline $\begin{array}{l}\text { MEA02.02 Review business } \\
\text { process controls effectiveness }\end{array}$ & $\mathrm{C}$ & I & $\mathrm{C}$ \\
\hline $\begin{array}{l}\text { MEA02.03 Perform control } \\
\text { self-assessments }\end{array}$ & $\mathrm{R}$ & I & $\mathrm{R}$ \\
\hline $\begin{array}{l}\text { MEA02.04 Identify and report } \\
\text { control deficiencies }\end{array}$ & $\mathrm{R}$ & I & $\mathrm{R}$ \\
\hline $\begin{array}{l}\text { MEA02.05 Ensure that } \\
\text { assurance provideers are } \\
\text { independent and qualified }\end{array}$ & - & - & - \\
\hline $\begin{array}{l}\text { MEA02.06 Plan assurance } \\
\text { initiatives }\end{array}$ & $\mathrm{C}$ & A & $\mathrm{C}$ \\
\hline $\begin{array}{l}\text { MEA02.07 Scope assurance } \\
\text { initiatives }\end{array}$ & $\mathrm{C}$ & - & $\mathrm{C}$ \\
\hline $\begin{array}{l}\text { MEA02.08 Execute assurance } \\
\text { initiatives }\end{array}$ & $\mathrm{C}$ & I & $\mathrm{C}$ \\
\hline
\end{tabular}

Berdasarkan tugas dan fungsi struktur organisasi di Diskominfotik Provinsi Riau pada bidang layanan e-government, bahwa Kepala Seksi (Kasi) Pengembangan Aplikasi Pemerintah, Kepala Seksi Pengembangan Aplikasi Publik dan Kepala Seksi Tata Kelola e-government cukup mewakili peran - peran yang ada pada key governance di COBIT 5. Responden tersebut dipilih karena jabatan atau bidang tersebut relevan atau berkaitan dengan penelitian, yaitu mengenai tata pengelolaan teknologi informasi yang berfokus pada monitoring, evaluasi, dan penilaian di Dinas Komunikasi Informatika dan Statistik Provinsi Riau.

\subsection{Perhitungan Capability Level}

1. Perhitungan Capability Level MEA02.

Pada penelitian ini digunakan teknik analisis data deskriptif kuantitatif yang menekankan pada sumber data dan fakta. Kemudian data dikembangkan dengan acuan pada capability level COBIT 5 dan skala pengukuran Guttman.

Rumus Menghitung Data Domain Capability Level yaitu:

$$
\mathrm{CL}_{\mathrm{i}}=\mathrm{NL}_{0}+\mathrm{NL}_{1}+\mathrm{NL}_{2}+\mathrm{NL}_{3}+\mathrm{NL}_{4}+\mathrm{NL}_{5}
$$

Rumus capability level keseluruhan pada setiap proses:

$$
\mathrm{CL}_{\mathrm{a}}=\frac{\sum \mathrm{CL}_{\mathrm{i}}}{\sum \mathrm{R}}
$$

Terdapat beberapa istilah yang digunakan, yaitu:
a. $\mathrm{P}=$ Proses
b. $\mathrm{R}=$ Responden
c. $\mathrm{L} 0=$ Level 0
d. $\mathrm{L} 1=$ Level 1
e. $\mathrm{L} 2=$ Level 2
f. L3 = Level 3
g. $\mathrm{L} 4=$ Level 4
h. L5 $=$ Level 5
i. $\mathrm{CL}=$ Capability Level.

\begin{tabular}{|c|c|c|c|c|c|c|c|c|}
\hline $\mathbf{P}$ & $\mathbf{R}$ & L0 & L1 & L2 & L3 & L4 & $\begin{array}{l}\mathbf{L} \\
5\end{array}$ & $\begin{array}{l}\mathbf{C} \\
\mathbf{L}\end{array}$ \\
\hline \multirow{3}{*}{$\begin{array}{c}\mathrm{ME} \\
\mathrm{A} \\
02 . \\
01\end{array}$} & $\begin{array}{c}\mathrm{R} \\
1\end{array}$ & 0 & 0 & 0 & 1,2 & 0,8 & 1 & 3 \\
\hline & $\begin{array}{l}\mathrm{R} \\
2\end{array}$ & 0 & 0 & 0 & 1,8 & 0,8 & 1 & 3,6 \\
\hline & $\begin{array}{l}\mathrm{R} \\
3\end{array}$ & 0 & 0 & 0 & 0,6 & 3,2 & 0 & 3,8 \\
\hline
\end{tabular}

Tabel 3. Perhitungan Capability Level MEA02.01 


$$
\mathrm{CL}_{\mathrm{a}}=\frac{\sum \mathrm{CL}_{\mathrm{i}}}{\sum \mathrm{R}}=\frac{10,4}{3}=3,47
$$

Tabel 4. Perhitungan Capability Level MEA02.02

\begin{tabular}{|c|c|c|c|c|c|c|c|c|}
\hline $\mathbf{P}$ & $\mathbf{R}$ & L0 & L1 & L2 & L3 & L4 & $\begin{array}{l} \\
5\end{array}$ & $\begin{array}{l}\mathbf{C} \\
\mathbf{L}\end{array}$ \\
\hline \multirow{3}{*}{$\begin{array}{c}\text { ME } \\
\text { A } \\
02 . \\
02\end{array}$} & $\begin{array}{l}\mathrm{R} \\
1 \\
\end{array}$ & 0 & 0 & 0 & 0,6 & 2,4 & 1 & 4 \\
\hline & $\begin{array}{l}\mathrm{R} \\
2\end{array}$ & 0 & 0 & 0 & 0,6 & 2,4 & 1 & 4 \\
\hline & $\begin{array}{l}\mathrm{R} \\
3\end{array}$ & 0 & 0 & 0 & 0,6 & 3,2 & 0 & 3,8 \\
\hline & & & & $=$ & $8=$ & & & $\begin{array}{c}11, \\
8\end{array}$ \\
\hline
\end{tabular}

Tabel 5. Perhitungan Capability Level MEA02.03

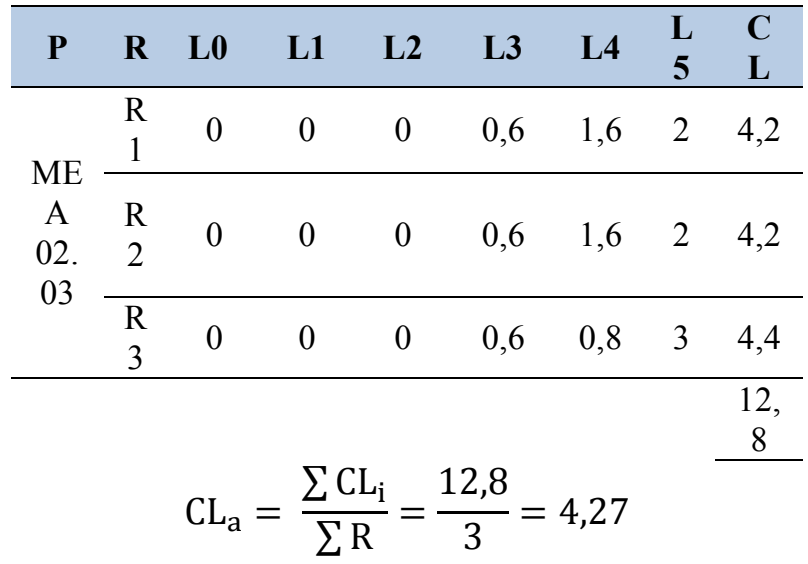

Tabel 6. Perhitungan Capability Level MEA02.04

\begin{tabular}{|c|c|c|c|c|c|c|c|c|}
\hline $\mathbf{P}$ & $\mathbf{R}$ & L0 & L1 & L2 & L3 & L4 & $\begin{array}{l}\mathbf{L} \\
5\end{array}$ & $\begin{array}{l}\text { C } \\
\text { L }\end{array}$ \\
\hline \multirow{3}{*}{$\begin{array}{c}\mathrm{ME} \\
\mathrm{A} \\
02 . \\
04\end{array}$} & $\begin{array}{l}\mathrm{R} \\
1 \\
\end{array}$ & 0 & 0 & 0 & 0,6 & 1,6 & 2 & 4,2 \\
\hline & $\begin{array}{l}\mathrm{R} \\
2\end{array}$ & 0 & 0 & 0 & 0,6 & 0,8 & 3 & 4,4 \\
\hline & $\begin{array}{l}\mathrm{R} \\
3\end{array}$ & 0 & 0 & 0 & 0,6 & 1,6 & 2 & 4,2 \\
\hline & & & & & & & & $\begin{array}{c}12 \\
8\end{array}$ \\
\hline
\end{tabular}

$$
\mathrm{CL}_{\mathrm{a}}=\frac{\sum \mathrm{CL}_{\mathrm{i}}}{\sum \mathrm{R}}=\frac{12,8}{3}=4,27
$$

\begin{tabular}{|c|c|c|c|c|c|c|c|c|}
\hline $\mathbf{P}$ & $\mathbf{R}$ & L0 & L1 & L2 & $\mathbf{L 3}$ & L4 & $\begin{array}{l}\mathbf{L} \\
5\end{array}$ & $\begin{array}{l}\text { C } \\
\mathbf{L}\end{array}$ \\
\hline \multirow{3}{*}{$\begin{array}{c}\mathrm{ME} \\
\mathrm{A} \\
02 . \\
05\end{array}$} & $\begin{array}{l}\mathrm{R} \\
1\end{array}$ & 0 & 0 & 0 & 0,6 & 2,4 & 1 & 4 \\
\hline & $\begin{array}{l}\mathrm{R} \\
2\end{array}$ & 0 & 0 & 0 & 0,6 & 3,4 & 0 & 4 \\
\hline & $\begin{array}{l}\mathrm{R} \\
3\end{array}$ & 0 & 0 & 0 & 0,6 & 2,4 & 1 & 4 \\
\hline & & & & $\frac{C L_{i}}{R}$ & $\frac{12}{3}$ & & & 12 \\
\hline
\end{tabular}

Tabel 7. Perhitungan Capability Level MEA02.05

Tabel 8. Perhitungan Capability Level MEA02.06

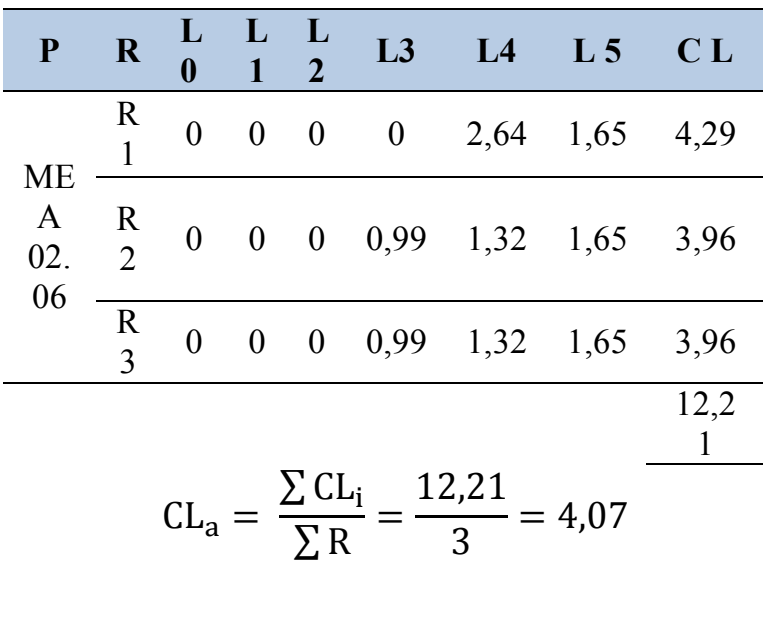

\begin{tabular}{|c|c|c|c|c|c|c|c|c|}
\hline $\mathbf{P}$ & $\mathbf{R}$ & $\begin{array}{l}\mathbf{L} \\
\mathbf{0}\end{array}$ & $\begin{array}{l}\mathrm{L} \\
\mathbf{1}\end{array}$ & $\begin{array}{l}\mathbf{L} \\
\mathbf{2}\end{array}$ & $\mathbf{L 3}$ & L4 & L 5 & C L \\
\hline \multirow{3}{*}{$\begin{array}{c}\mathrm{ME} \\
\mathrm{A} \\
02 . \\
07\end{array}$} & $\begin{array}{l}\mathrm{R} \\
1 \\
\end{array}$ & 0 & 0 & 0 & 0,99 & 2,64 & 0 & 3,63 \\
\hline & $\begin{array}{l}\mathrm{R} \\
2\end{array}$ & 0 & 0 & 0 & 0,99 & 2,64 & 0 & 3,63 \\
\hline & $\begin{array}{l}\mathrm{R} \\
3 \\
\end{array}$ & 0 & 0 & 0 & 0,99 & 2,64 & 0 & 3,63 \\
\hline & & & & & & & & $\begin{array}{c}10,8 \\
9\end{array}$ \\
\hline
\end{tabular}

Tabel 9. Perhitungan Capability Level MEA02.07 
Tabel 10. Perhitungan Capability Level MEA02.08

\begin{tabular}{|c|c|c|c|c|c|c|c|c|}
\hline $\mathbf{P}$ & $\mathbf{R}$ & $\begin{array}{l}\text { L } \\
\mathbf{0}\end{array}$ & $\begin{array}{l}\mathrm{L} \\
\mathbf{1}\end{array}$ & $\begin{array}{l}\mathbf{L} \\
\mathbf{2}\end{array}$ & $\mathbf{L 3}$ & L4 & L 5 & C L \\
\hline \multirow{3}{*}{$\begin{array}{c}\mathrm{ME} \\
\mathrm{A} \\
02 . \\
08\end{array}$} & $\begin{array}{l}\mathrm{R} \\
1 \\
\end{array}$ & 0 & 0 & 0 & 0,99 & 2,64 & 0 & 3,63 \\
\hline & $\begin{array}{l}\mathrm{R} \\
2\end{array}$ & 0 & 0 & 0 & 0 & 4 & 0 & 4 \\
\hline & $\begin{array}{l}\mathrm{R} \\
3 \\
\end{array}$ & 0 & 0 & 0 & 0,99 & 2,64 & 0 & 3,63 \\
\hline & & & & & & & & $\begin{array}{c}11,2 \\
6\end{array}$ \\
\hline
\end{tabular}

\subsection{Hasil Perhitungan Keseluruhan Capability Level.}

Selanjutnya dilakukan perhitungan keseluruhan dari semua nilai Capability level.

$$
\mathrm{C}=\frac{\sum \mathrm{CL}_{a}}{\sum \mathrm{P}_{0}}
$$

$$
\begin{gathered}
\text { CL mea02.01 + mea02.02 + mea02.03 } \\
\text { + mea02.04 + mea02.05 }
\end{gathered}
$$$$
=\frac{+ \text { mea } 02.06+\text { mea } 02.07+\text { mea } 02.08}{\text { on }}
$$$$
\text { Jumlah proses setiap domain }-8
$$

$$
\begin{aligned}
& =\frac{3,47+3,93+4,27+4,27+4+4,07}{8} \\
& =\frac{31,39}{8}=3,92
\end{aligned}
$$

Tabel I0. Hasil perhitungan keseluruhan Capability Level

\begin{tabular}{clcc}
$\begin{array}{c}\text { Proses } \\
\text { IT }\end{array}$ & Nama Proses & $\begin{array}{c}\text { Current } \\
\text { Capability }\end{array}$ & $\begin{array}{c}\text { Expected } \\
\text { Capability }\end{array}$ \\
\hline \multirow{3}{*}{ MEA02 } & $\begin{array}{l}\text { Memantau, } \\
\text { mengevaluasi, } \\
\text { dan menilai } \\
\text { sistem } \\
\text { pengendalian } \\
\text { internal }\end{array}$ & 3,92 & 5 \\
\hline
\end{tabular}

(Monitor,

Evaluate and

Assess the

System of the

Internal

Control)

Nilai yang ada saat ini / Current Capability yaitu pada nilai 3,92 yang berarti tatakelola TI pada diskominfotik provinsi Riau sudah baik, namun belum terpenuhi secara keseluruhan dan belum mencapai tujuan yang diharapkan oleh Diskominfotik Provinsi Riau. Sedangkan nilai yang diharapkan / expected capability dalam pengelolaan teknologi informasi pada domain Monitor, Evaluate and Assess (MEA02) yaitu pada nilai 5.

\section{Kesimpulan}

Berdasarkan uraian pada bab sebelumnya, maka dapat disimpulkan bahwa setelah dilakukan evaluasi ditemukan hasil capability level, tingkat kematangan tata kelola teknologi informasi pada Dinas Komunikasi Informatika dan Statistik Provinsi Riau di bidang layanan e-government menggunakan domain MEA02 berada pada level 3,92, atau dapat dimaksud bahwa pencapaian pada setiap prosesnya belum terpenuhi secara keseluruhan dan belum mencapai tujuan yang diharapkan oleh Diskominfotik Provinsi Riau.

\section{Saran}

Penelitian ini dapat dijadikan sebagai acuan ataupun bahan pertimbangan oleh Dinas Komunikasi Informatika dan Statistik Provinsi Riau dalam menentukan arah kebijakan kedepannya berdasarkan hasil evaluasi ini. Serta untuk penelitian lanjutan dapat menggunakan domain lainnya didalam cobit 5 dengan permasalahan yang relevan.

\section{Daftar Pustaka}

[1] Sihotang, H. T., \& Sagala, J. R. (2015). Penerapan Tata Kelola Teknologi Informasi Dan Komunikasi Pada Domain Align, Plan And Organise ( APO ) Dan Monitor , Evaluate And Assess ( MEA ) 
Dengan Menggunakan Framework Cobit 5 Studi Kasus: Stmik Pelita Nusantara Medan. Jurnal Mantik Penusa, 18(2), 9096.

[2] Prasetyo, A., \& Mariana, N. (2011). Analisis Tata Kelola Teknologi Informasi ( It Governance ) pada Bidang Akademik dengan Cobit Frame Work Studi Kasus pada Universitas Stikubank Semarang. Jurnal Teknologi Informasi DINAMIK, 16(2), 139-149

[3] Satria, F., \& Hartati, S. (2015). Pemanfaatan E-Government Sebagai Media Promosi di Bidang Pariwisata Ekonomi Kreatif ( Studi Kasus: Dinas Pariwisata Ekonomi Kreatif, Kabupaten Pesawaran ). Journal Technology Acceptance Model, 5, 80-87
[4] Wardani, S., \& Puspitasari, M. (2014). Audit Tata Kelola Teknologi Informasi Menggunakan Framework COBIT dengan Model Maturity Level ( Studi Kasus Fakultas ABC ). Jurnal Teknologi, 7(1), $38-46$

[5] Information Systems Audit and Control Association, Ed., COBIT 5: a business framework for the governance and management of Enterprise IT: an ISACA ${ }^{\circledR}$ framework. Rolling Meadows, Ill: ISACA, 2012. 